\title{
Efeito do Alho (Allium sativum Linn.), Probiótico e Virginiamicina Antes, Durante e Após o Estresse Induzido pela Muda Forçada em Poedeiras Semipesadas
}

\author{
José Humberto Vilar da Silva ${ }^{1}$, José Jordão Filho ${ }^{2}$, Edson Lindolfo da Silva ${ }^{2}$
}

\begin{abstract}
RESUMO - Foram realizados três experimentos com 336 poedeiras no segundo ciclo de produção e 24 meses de idade, alojadas em condições de criação comercial $\left(550 \mathrm{~cm}^{2} /\right.$ ave $)$. O objetivo foi avaliar o alho $(5 \mathrm{~kg} / \mathrm{t})$, probiótico $(300 \mathrm{~g} / \mathrm{t})$ e a virginiamicina $(20 \mathrm{~g} / \mathrm{t}) \mathrm{como}$ aditivos de rações antes, durante e após o estresse induzido pela muda forçada (MF). O delineamento experimental foi o inteiramente ao acaso e os tratamentos usados foram: dieta controle (DC); DC+alho (A); DC+probiótico (P); DC+virginiamicina (V); DC+A+V; DC+A $+\mathrm{P} ; \mathrm{DC}+\mathrm{P}+\mathrm{V} ; \mathrm{DC}+\mathrm{A}+\mathrm{P}+\mathrm{V}$, constituídos por sete repetições de seis aves. O período pré-experimental foi de 15 dias e o fotoperíodo, de 17 horas de luz/dia. O ensaio 1 foi realizado em quatro semanas antes da MF, com as aves recebendo $110 \mathrm{~g}$ de ração contendo os aditivos. O ensaio 2 foi realizado durante os doze dias de MF, com as aves recebendo $10 \mathrm{~g}$ de milho moído, usado como veículo para diluir a dose dos aditivos consumida em $110 \mathrm{~g}$ de ração. O ensaio 3 foi realizado em seis semanas, durante o terceiro ciclo de produção, com as aves recebendo $110 \mathrm{~g}$ de ração, sem os aditivos, e as coletas tiveram início após as aves terem atingido 50\% de postura. Antes da MF, o alho reduziu a massa de ovos em relação ao probiótico (48,2 vs. 39,8 g) e, durante a MF, a virginiamicina e a mistura P+V reduziram a porcentagem de intestinos em relação ao alho (7,51 e 7,72 vs. 9,43), mas o peso e a porcentagem de baço não foram alterados. Após a MF, as variáveis não foram afetadas pelos tratamentos. Nas condições do experimento, os antimicrobianos usados não melhoram o desempenho de poedeiras antes, durante e após o estresse induzido pela MF em relação à ração sem aditivos.
\end{abstract}

Palavras-chave: aditivos, antimicrobianos, estresse, produção de ovos

\section{Effect of Bulb Garlic (Allium sativum Linn.), Probiotic and Virginiamycin Before, During and After Induced Forced Molt Stress in Semi-Heavily Laying Hens}

\begin{abstract}
Three trials were carried out with 336 laying hens, aging 24 weeks and after second forced molt, caged in commercial conditions $\left(550 \mathrm{~cm}^{2} / \mathrm{bird}\right)$ to evaluate the use of bulb garlic $(5 \mathrm{~kg} / \mathrm{t})$, probiotic $(300 \mathrm{~g} / \mathrm{t})$ and virginiamycin $(20 \mathrm{~g} / \mathrm{t})$ as additives in laying hens diet before, during and after the induced forced molt stress (FM). A completely randomized design, with seven replicates of six brids each, was used. The treatments consisted of a control diet (CD) supplemented with bulb garlic (G), probiotic (P) and virginiamycin $(\mathrm{V}$, ) resulting in treatments: $\mathrm{CD}+\mathrm{G} ; \mathrm{CD}+\mathrm{P} ; \mathrm{CD}+\mathrm{V} ; \mathrm{CD}+\mathrm{G}+\mathrm{V} ; \mathrm{CD}+\mathrm{P}+\mathrm{G} ; \mathrm{CD}+\mathrm{P}+\mathrm{V} ; \mathrm{CD}+\mathrm{G}+\mathrm{P}+\mathrm{V}$. The pre-experimental period lasted 15 days, where the birds were under a photoperiod of $17 \mathrm{~h}$ of light: $7 \mathrm{~h}$ of dark. The trial 1 was carried out during four weeks before FM, where the birds were fed $110 \mathrm{~g}$ of diet with the additives. The trial 2 was conducted during FM (12 days), where the birds were fed diet with $10 \mathrm{~g}$ of corn ground, used to reduce the amount fed in $110 \mathrm{~g}$ of diet. The trial 3 was carried out in the postmolt period, where the birds were fed $110 \mathrm{~g}$ of diet without additive, and the collection period began when birds showed over $50 \%$ of egg production. Before FM, bulb garlic decreased the egg mass in comparison to probiotic (48.2 vs. 39.8). During FM, virginiamycin and P+V mixture decreased intestinal percentage in relation to bulb garlic (7.51 and 7.72 vs. 9.43), but weight and percentage of spleen were not affected. After FM, the variables were not affected by the treatments. Bulb garlic, probiotic and virginiamycin showed no effect on semi-heavily laying hens performance, before, during and after induced FM stress in relation to the diet without additives.
\end{abstract}

Key Words: additives, antimicrobes, egg production, stress

\section{Introdução}

Vários questionamentos têm sido feitos sobre o uso de antibióticos em rações para promover o desempenho de aves, em virtude da possível presença de resíduos em carne e ovos que possam alterar o balanço microbiano intestinal, contribuindo para $\mathrm{o}$ surgimento de resistência em patógenos humanos. $\mathrm{O}$ aumento da demanda por alimentos de origem animal com selo orgânico, tem realçado a importância dos extratos herbais como aditivos antimicrobianos em rações animais. Portanto, os aditivos de rações devem atender as exigências de segurança alimentar dos consumidores, e o alho, por fazer parte da culinária humana, assim como os probióticos, que são constituídos por microorganismos da flora benéfica, 
têm se mostrado como opções interessantes aos antibióticos convencionais.

O alho contém a alicina, sintetizada pela enzima alinase a partir da alina (Ceci et al., 1991) com o rompimento das células do bulbo (Prasad et al., 1996; Yu \& Wu, 1989a,b). A alicina é reconhecida como bactericida, fungicida e antioxidante há pelo menos 5000 anos por babilônicos, egípcios, fenícios, viquingues, chineses, gregos, romanos e hindus (Block, 1985; Song \& Milner, 2001; Matsuura, 2001), exibindo ação antibiótica de largo espectro contra as bactérias gram positiva e gram negativa, sem contribuir para aumentar a resistência bacteriana e, em combinação com antibióticos, resulta em sinergismo de ação parcial ou total contra bactérias (Sivam, 2001).

Segundo Coates (1963) e Roura et al. (1992), a eficácia de um promotor de crescimento depende da contaminação ambiental e da intensidade do desafio que o organismo da ave está exposto. Trabalhando com pintos alojados em baterias, Freitas et al. (2001) não observaram efeito do alho $(0,0,2,0,4$ e $0,6 \%)$, da bacitracina de zinco $(0,0025 \%)$ e da lincomicina $(0,001 \%)$ sobre o desempenho das aves. Ao contrário, quando os frangos foram alojados em cama de palha de café, Takaki et al. (1998) constataram efeito benéfico do alho.

A muda forçada é aplicada com a finalidade de prolongar a produção econômica das galinhas poedeiras (Silva \& Santos, 1999), causando além da suspensão da postura, perdas de peso e de penas, alterações fisiológicas importantes como aumento da concentração dos hormônios adrenocortical e corticosterona (Davis et al., 2000), afetando a função imune no oviduto (Yoshimura et al., 1997). Portanto, a muda forçada deve ser um estágio crítico, do ponto de vista imunológico, para testar a eficácia dos antimicrobianos. Holt \& Porter (1992) atribuíram o agravamento das infecções causadas por Salmonellas enteritidis, durante MF de 14 dias de duração, à imunocompetência celular. Recentemente, Holt \& Gast (2002) observaram aumento significativo nos níveis séricos da a 1 Glicoproteína ácida, uma proteína de fase aguda, em poedeiras submetidas a muda forçada, pela restrição alimentar durante 10 dias, em comparação com às não submetidas. Segundo Davis et al. (2000), o aumento da relação heterofil: linfócitos e dos níveis de corticosterona durante a MF também pode ser usado como indicadores do estresse fisiológico nas aves. Em contraste, Alodan \& Mashaly (1996) não constataram efeito de três métodos de muda forçada sobre a imunocompetência e mortalidade das aves.

Em virtude da falta de informações e contradição entre os autores, mais estudos devem contribuir para elucidar o papel da muda forçada na imunodepressão e desempenho posterior das aves. Nenhum tratamento preventivo contra a colonização do trato digestivo por patógenos tem sido testado durante o estresse induzido pela muda forçada. Portanto, será que o fornecimento de substâncias antimicrobianas antes e durante a fase de restrição alimentar melhora o balanço microbiano intestinal, promovendo a saúde do epitélio e o desempenho das aves durante o ciclo de postura seguinte?

O objetivo do trabalho foi avaliar o efeito do alho em comparação com o probiótico e virginiamicina como aditivos antimicrobianos em poedeiras antes, durante e após o estresse fisiológico induzido pela muda forçada.

\section{Material e Métodos}

\section{Local e tratamentos experimentais}

O experimento foi realizado no Aviário do Centro de Formação de Tecnólogos, Campus de Bananeiras da UFPB.

Foram utilizados 336 poedeiras Lohmann Brown entre o segundo e o terceiro ciclos de postura, com 24 meses de idade e peso vivo de $1,70 \mathrm{~kg}$, alojadas em condições de criação comercial numa densidade de $550 \mathrm{~cm}^{2}$. As aves foram submetidas a um programa de luz de 17 horas de duração. Uma dieta controle (DC), sem aditivo, foi formulada conforme as recomendações de Rostagno et al. (2000) para atender as exigências das aves em todos os nutrientes (Tabela 1). Posteriormente, esta DC foi suplementada com alho $(\mathrm{A})$, probiótico $(\mathrm{P})$, virginiamicina $(\mathrm{V})$ e as misturas $\mathrm{A}+\mathrm{V}, \mathrm{P}+\mathrm{A}, \mathrm{P}+\mathrm{V}$ e $\mathrm{P}+\mathrm{A}+\mathrm{V}$.

O probiótico utilizado foi o Carlsporin B-300, em nível de $300 \mathrm{~g} / \mathrm{t}$ de ração e o alho foi adquirido no mercado local, depois processado e misturado à ração na base de 0,5\% (Takaki et al., 1997). Para prevenir eventuais perdas de atividade durante um longo período de armazenamento, o probiótico e o alho foram adicionados semanalmente à ração. A virginiamicina (Stafac - 50\%) foi usada na proporção de $20 \mathrm{~g} / \mathrm{t}$ de ração (Teeter \& Belay, 1996).

A temperatura e umidade relativa do ar foram registradas duas vezes ao dia (8 e $17 \mathrm{~h}$ ), utilizando-se um aparelho digital localizado no centro do galpão. A 
temperatura média do período foi de $27,9^{\circ} \mathrm{C}$, com médias mínima e máxima, respectivamente, de $22,2 \mathrm{e}$ $32,0 .{ }^{\circ} \mathrm{C}$, enquanto a umidade relativa média foi de $70,2 \%$, com mínima e máxima, respectivamente, de 52,9 e $90,6 \%$.

\section{Experimento 1}

Antes da muda forçada (MF), as aves foram pesadas e submetidas a um período pré-experimental de 15 dias. Decorrido este período, as aves passaram a receber $110 \mathrm{~g}$ de ração/dia durante as quatro semanas de coleta.

As variáveis estudadas nesta fase foram consumo de ração, produção e peso dos ovos, massa e conversão por massa de ovos.

\section{Experimento 2}

A muda forçada foi realizada, pela retirada da ração dos comedouros durante 12 dias, mantendo a oferta de água à vontade. Durante a muda forçada, o programa de luz foi suspenso e, o consumo dos aditivos foi mantido em nível similar ao ensaio anterior, pela diluição da dose consumida em 110 g de ração em $10 \mathrm{~g}$ de milho moído, utilizado como veículo.

Foram avaliados a produção, peso e gravidade específica dos ovos, pesos e porcentagens de intestino e baço e a perda de peso vivo. Também foram estudados os pesos e as porcentagens de gema, clara e casca. Para avaliação da porcentagem do intestino, do duodeno até a cloaca, e do baço em relação ao peso vivo, foram selecionadas e abatidas 56 aves, uma de cada parcela experimental, por deslocamento cervical.

A qualidade da casca foi medida pela quebra e secagem das cascas em estufa a $105^{\circ} \mathrm{C}$ durante quatro horas e a gravidade específica foi estimada pela relação entre o peso do ovo no ar e o peso de deslocamento da água pelo peso do ovo, quando completamente imerso em $1 \mathrm{~L}$ de água destilada com temperatura mantida a $23^{\circ} \mathrm{C}$, utilizando-se uma balança com precisão de $0,01 \mathrm{~g}$ e a seguinte expressão (Hempe et al., 1988):

$$
\mathrm{GE}=\frac{\text { Peso do ovo no ar }(\mathrm{g})}{\begin{array}{c}
\text { Peso de deslocamento da } \\
\text { água }(\mathrm{g}) \times \mathrm{FC}
\end{array}}
$$

em que $\mathrm{FC}=$ fator de correção da temperatura da água a $23^{\circ} \mathrm{C}=0,99754$, é o valor da densidade dependente da temperatura da água no beacker.
Tabela 1 - Composição percentual da ração controle ${ }^{1}$ Table 1 - Percentage composition of control diet as fed (\%)

Ingredientes (Ingredients) $\quad \%$

Milho, 8,8 \% PB (Corn grain) $\quad 65,62$

Farelo de soja, 45,0 \%PB (Soybean meal) 22,76

Calcário (Limestone) $\quad 8,62$

Fosfato bicálcico (Dicalcium phosphate) $\quad 1,30$

DL-metionina, 99\% (DL-methionine) $\quad 0,15$

$\mathrm{L}$-lisina $\cdot \mathrm{HCl}($ L-lysine $\bullet \mathrm{HCl}) \quad 0,12$

Óleo vegetal (Vegetable oil) $\quad 0,30$

Premix vitamínico $^{2} \quad 0,10$

Premix mineral $^{3} \quad 0,05$

Sal comum (Vegetable oil) $\quad 0,43$

$\mathrm{BHT}^{3} \quad 0,01$

Areia lavada ${ }^{4}$ (Washed sand) $\quad 0,54$

Composição calculada (Calculated composition)

$\mathrm{EM}, \mathrm{kcal} / \mathrm{kg}$ (Metabolizable energy) $\quad 2.800$

Cálcio, \% (Calcium) 3,65

Fósforo disponível, \% (Available phosphorus) $\quad 0,34$

Lisina, \% (Lysine) $\quad 0,72$

Metionina+cistina, \% (Methionine+Cystine) $\quad 0,62$

Sódio, \% (Sodium) 0,20

${ }^{1}$ Recomendações de acordo com Rostagno et al. (2000)

(Requeriments according to Rostagno et al. [2000]).

2 Composição básica por $\mathrm{kg}$ do produto (basic composition by $\mathrm{kg}$ of product): Vit. A 10.000.000 UI; Vit. E 6.000 UI; Vit. K, 600 mg; Vit. $\mathrm{B}_{12}$ 11.000; Niacina (Niacin) 25.000 mg, Ácido fólico (Folic acid) 400 mg; Ácido pantotênico (Panthotenic acid) 10.000 mg; Selênio (Selenium) $300 \mathrm{mg}$; Antioxidante (Antioxidant) $20 \mathrm{~g}$. Veículo (vehicle) q.s.p.

3 Composição básica por $\mathrm{kg}$ do produto (basic composition by kg of product): Mg 150.000 mg; Fe 100.000 mg; Cu 16.000 mg; I $1.500 \mathrm{mg}$. Veículo (vehicle) q.s.p.

${ }^{4}$ Inerte (inert).

\section{Experimento 3}

Após a MF, as aves foram paulatinamente adaptadas a ingestão de alimentos, durante 15 dias, com o fornecimento de cotas crescente de milho moído. Completada esta fase, as rações sem aditivos passaram a ser fornecidas na quantidade de $110 \mathrm{~g} /$ ave/dia e as coletas foram reiniciadas quando as aves atingiram cerca de $50 \%$ de produção de ovos.

Foram avaliados os efeitos residuais dos aditivos antimicrobianos sobre o consumo de ração, produção, peso, massa, conversão por massa e gravidade específica dos ovos.

\section{Análises estatísticas}

O delineamento experimental utilizado foi o inteiramente ao acaso, com oito tratamentos, cada um com sete repetições de seis aves. As médias dos tratamentos foram analisadas pelo teste $\mathrm{F}(\mathrm{P}<0,05)$ e, quando houve efeito significativo, as médias dos diferentes tratamentos foram comparadas entre si pelo teste Student Newman Keuls $(\mathrm{P}<0,05)$, utilizando o programa SAEG (UFV, 1982). 


\section{Resultados e Discussão}

\section{Experimento 1. Resultados antes da muda forçada}

Antes da muda forçada, as rações contendo alho ou a mistura $\mathrm{A}+\mathrm{P}+\mathrm{V}$ afetaram negativamente $\mathrm{o}$ consumo em comparação com os tratamentos contendo $\mathrm{V}$ e a mistura $\mathrm{A}+\mathrm{P}(\mathrm{P}<0,05)$.

Observa-se que o efeito do alho sobre o consumo foi inconsistente, em virtude do tratamento contendo $\mathrm{A}+\mathrm{P}$ melhorou o consumo, enquanto os tratamentos contendo alho ou a mistura $\mathrm{A}+\mathrm{P}+\mathrm{V}$ pioraram (Tabela 2). Resultado semelhante foi obtido por Freitas et al. (2001) com frangos de corte.

Em virtude da falta de um padrão de comportamento alimentar das aves frente à inclusão dos aditivos, não foi possível especular sobre os possíveis fatores e mecanismos fisiológicos envolvidos, embora informações anteriores mostraram que a inclusão de alho diretamente no estômago causou irritação na mucosa intestinal de cães, aparecimento de vermelhidão na mucosa e perda das células epiteliais do topo das criptas do íleo (Hoshiro et al., 2001).

A produção de ovos, o peso dos ovos e a conversão alimentar por massa de ovos não foram afetados pelos tratamentos $(\mathrm{P}>0,05)$. O probiótico melhorou a massa de ovos em comparação com o tratamento contendo alho $(\mathrm{P}<0,05)$, sem diferir dos demais tratamentos. O tratamento contendo alho e virginiamicina pioraram, respectivamente, 10 e $5 \%$ a conversão alimentar por massa de ovos, enquanto o probiótico melhorou $6 \%$, em comparação com o resultado obtido com a dieta controle (Tabela 2). O tratamento $\mathrm{A}+\mathrm{V}$ piorou a conversão alimentar por massa de ovos em $1,2 \%$, enquanto o $\mathrm{P}+\mathrm{V}$ melhorou em $10 \%$ em relação ao tratamento controle.

Um fato secundariamente observado, mas com possível valor biosanitário importante, foi a redução na freqüência de pardais nos comedouros contendo alho na ração.

Experimento 2. Resultados durante a muda forçada

Durante a muda forçada, a produção, o peso e a gravidade específica dos ovos produzidos nos três primeiros dias da suspensão do fornecimento de ração e os pesos do baço e do intestino no final da muda forçada, assim como a porcentagem de baço, não foram afetados pelos tratamentos $(\mathrm{P}>0,05)$. Entretanto, a virginiamicina e a mistura probiótico com virginimiacina reduziram $(\mathrm{P}<0,05)$ a porcentagem do trato digestivo em relação ao tratamento contendo alho (Tabela 3 ).

O efeito da virginiamicina na redução da massa do trato gastrointestinal tem sido observado (Teeter \& Belay, 1996), podendo estar relacionado à diminuição da inflamação da parede intestinal (Walton, 1990) e à melhor absorção de nutrientes e ao menor gasto de mantença, com a renovação do epitélio intestinal (Teeter \& Belay, 1996).

Ao contrário, a tendência de os tratamentos contendo alho na ração causarem aumento da porcentagem de trato gastrointestinal pode estar relacionada com o efeito irritante do alho sobre a mucosa intestinal, conforme observado por Hoshiro et al. (2001) em

Tabela 2 - Efeitos de diferentes aditivos sobre consumo de ração (CR), produção de ovos (PR), peso dos ovos (PO), massa de ovos (MO) e conversão por massa de ovos (CMO), antes da muda forçada

Table 2 - Effect of different additives on feed intake (FI), egg production (EP), egg weight (EW) and feed to egg mass ratio (EMR), before forced molt

\begin{tabular}{lccccc}
\hline Tratamentos $^{1}$ & $\mathrm{CR}(\mathrm{g})$ & $\mathrm{PR}(\%)$ & $\mathrm{PO}(\mathrm{g})$ & $\mathrm{MO}(\mathrm{g})$ & $\mathrm{CMO}(\mathrm{kg} / \mathrm{kg})$ \\
Treatments & $F I$ & $E P$ & $E W$ & $E M$ & $E M R$ \\
\hline $\mathrm{DC}(C D)$ & $110,3^{\mathrm{ab}}$ & 73,2 & 62,5 & $45,7^{\mathrm{ab}}$ & 2,42 \\
$\mathrm{DC}+\mathrm{P}(C D+P)$ & $109,9^{\mathrm{ab}}$ & 75,1 & 64,2 & $48,2^{\mathrm{a}}$ & 2,28 \\
$\mathrm{DC}+\mathrm{A}(C D+G)$ & $105,4^{\mathrm{b}}$ & 63,0 & 63,3 & $39,8^{\mathrm{b}}$ & 2,68 \\
$\mathrm{DC}+\mathrm{V}(C D+V)$ & $112,6^{\mathrm{a}}$ & 71,1 & 63,3 & $45,0^{\mathrm{ab}}$ & 2,55 \\
$\mathrm{DC}+\mathrm{P}+\mathrm{V}(C D+P+V)$ & $109,6^{\mathrm{ab}}$ & 66,3 & 62,4 & $41,3^{\mathrm{ab}}$ & 2,69 \\
$\mathrm{DC}+\mathrm{A}+\mathrm{V}(C D+G+V)$ & $108,9^{\mathrm{ab}}$ & 73,1 & 62,4 & $45,6^{\mathrm{ab}}$ & 2,39 \\
$\mathrm{DC}+\mathrm{A}+\mathrm{P}(C D+G+P)$ & $112,8^{\mathrm{a}}$ & 70,9 & 62,1 & $44,0^{\mathrm{ab}}$ & 2,59 \\
$\mathrm{DC}+\mathrm{A}+\mathrm{P}+\mathrm{V}(C D+G+P+V)$ & $105,8^{\mathrm{b}}$ & 70,6 & 64,1 & $45,2^{\mathrm{ab}}$ & 2,40 \\
$\mathrm{CV}(\%)$ & 3,32 & 10,39 & 4,10 & 10,91 & 11,49 \\
\hline
\end{tabular}

${ }^{1} \mathrm{DC}=$ dieta controle; $\mathrm{P}=$ probiótico; $\mathrm{A}=$ alho e $\mathrm{V}=$ virginiamicina .

$a, b$ Médias seguidas de diferentes letras são diferentes $(P<0,05)$ pelo teste SNK.

${ }^{1} C D=$ Control diet; $P=$ probiotic; $G=$ garlic and $V=$ virginiamycin .

a,b Means followed by different letters are different $(P<.05)$ by SNK test. 
Tabela 3 - Efeitos de diferentes aditivos sobre produção de ovos (PR), peso dos ovos (PO), gravidade específica (GE), pesos e porcentagens de intestino (INT) e de baço (\%BÇ), durante a muda forçada

Table 3 - Effects of different additives on egg production (EP), egg weight (EW), specific gravity (SG), weights and percentages of intestine (INT) and spleen (SP), during the forced molt

\begin{tabular}{|c|c|c|c|c|c|c|c|}
\hline $\begin{array}{l}\text { Tratamentos }{ }^{1} \\
\text { Treatments }\end{array}$ & $\begin{array}{l}\mathrm{PR}(\%) \\
E P\end{array}$ & $\begin{array}{c}\mathrm{PO}(\mathrm{g}) \\
E W\end{array}$ & $\begin{array}{l}\mathrm{GE} \\
S G\end{array}$ & $\begin{array}{l}\text { INTg } \\
\text { INTg }\end{array}$ & $\begin{array}{l}\% \mathrm{INT} \\
\% I N T\end{array}$ & $\begin{array}{c}\mathrm{BÇg} \\
S P\end{array}$ & $\begin{array}{l}\% \mathrm{BC} \\
\% S P\end{array}$ \\
\hline $\mathrm{DC}(C D)$ & 26,4 & 60,3 & 1,0661 & 112,4 & $8,52^{\mathrm{ab}}$ & 1,89 & 0,14 \\
\hline $\mathrm{DC}+\mathrm{P}(C D+P)$ & 28,0 & 60,4 & 1,0678 & 115,4 & $8,46^{\mathrm{ab}}$ & 2,10 & 0,15 \\
\hline $\mathrm{DC}+\mathrm{A}(C D+G)$ & 29,1 & 62,0 & 1,0733 & 120,2 & $9,43^{\mathrm{a}}$ & 2,00 & 0,15 \\
\hline $\mathrm{DC}+\mathrm{V}(C D+V)$ & 29,7 & 60,6 & 1,0685 & 99,3 & $7,51^{\mathrm{b}}$ & 2,06 & 0,16 \\
\hline $\mathrm{DC}+\mathrm{P}+\mathrm{V}(C D+P+V)$ & 27,4 & 59,2 & 1,0689 & 106,7 & $7,72^{b}$ & 2,09 & 0,15 \\
\hline $\mathrm{DC}+\mathrm{A}+\mathrm{V}(C D+G+V)$ & 30,3 & 61,0 & 1,0686 & 103,9 & $8,14^{\mathrm{ab}}$ & 1,72 & 0,14 \\
\hline $\mathrm{DC}+\mathrm{A}+\mathrm{P}(C D+G+P)$ & 30,2 & 60,7 & 1,0682 & 106,5 & $8,33^{\mathrm{ab}}$ & 2,00 & 0,16 \\
\hline $\mathrm{DC}+\mathrm{A}+\mathrm{P}+\mathrm{V}(C D+G+P+V)$ & 27,9 & 59,7 & 1,0685 & 112,1 & $8,43^{\mathrm{ab}}$ & 2,22 & 0,17 \\
\hline CV $(\%)$ & 10,72 & 5,66 & 0,92 & 21,78 & 11,24 & 21,78 & 21,78 \\
\hline
\end{tabular}

1 DC = dieta controle; $P$ = probiótico; $A$ = alho; $V=$ virginiamicina.

a,b Médias seguidas de diferentes letras são diferentes $(P<0,05)$ pelo teste SNK.

$1 C D=$ control diet; $P$ = probiotic; $G=$ garlic; $V=$ virginiamycin.

a,b Means followed by different letters are different $(P<.05)$ by SNK test.

cães, provocando, possivelmente, o engrossamento da mucosa intestinal.

Apesar de alguns estudos indicarem que a MF afeta os diferentes componentes do sistema imune das aves (Bem Nathan et al., 1977; Holt \& Porter, 1992) como o peso do timo e do baço (Brake et al., 1981), este último não sofreu alteração no presente estudo, embora as aves tenham sido alojadas sob densidade de $550 \mathrm{~cm}^{2} /$ ave, semelhante aquela das granjas comerciais, e em condições de alta temperatura ambiente (máxima de $32^{\circ} \mathrm{C}$ ).

No final da MF, os tratamentos não influenciaram a perda de peso e a porcentagem de perda de peso das aves $(\mathrm{P}>0,05)$, conforme a Tabela 4. Observa-se que a porcentagem de perda de peso das aves, em média, de 28 a $29 \%$ foi maior que aquela obtida por
Silva et al. (1999) e atende a recomendação de Baker et al. (1983) de uma perda de peso próxima a $28 \%$ para que as aves apresentem ótimo desempenho produtivo no ciclo seguinte de postura.

A mortalidade durante a muda forçada foi de $1 \%$, considerada baixa em relação a muda convencional, e somente ocorreu no tratamento contendo virginiamicina. Este resultado sugere o uso de uma cota diária de $10 \mathrm{~g}$ de fubá de milho durante a muda forçada como atenuante do estresse fisiológico induzido pela restrição total da ração durante 12 a 14 dias, melhorando o bem-estar das aves em processo de muda forçada.

A GE caiu linearmente $(\mathrm{P}<0,001)$ numa taxa de 0,0086/dia de muda forçada, conforme a equação: $\mathrm{Y}=1,08580-0,00864006 \mathrm{X}, \mathrm{R}^{2}=0,92$, em que $\mathrm{Y}$

Tabela 4 - Peso vivo inicial (PVI) e efeitos de diferentes aditivos sobre peso vivo final (PVF), perda de peso (PP) e porcentagem de perda de peso (\%PP) no início e final da muda forçada

Table 4 - Initial weight live (IWL) and effect of different additives on final weight live (FWL), weight loss (WLO) and weight loss percentage (\%WLO), in the beginning and final of forced molt

\begin{tabular}{|c|c|c|c|c|}
\hline Tratamentos & PVI $(g)$ & $\operatorname{PVF}(g)$ & $\mathrm{PP}(\mathrm{g})$ & \%РP \\
\hline Treatments & $I W L$ & $F W L$ & $W L O$ & $\% W L O$ \\
\hline $\mathrm{DC}(C D)$ & 1707,0 & 1256,7 & 450,3 & 26,42 \\
\hline $\mathrm{DC}+\mathrm{P}(C D+P)$ & 1723,6 & 1240,1 & 483,6 & 28,03 \\
\hline $\mathrm{DC}+\mathrm{A}(C D+G)$ & 1661,9 & 1177,7 & 484,2 & 29,13 \\
\hline $\mathrm{DC}+\mathrm{V}(C D+V)$ & 1707,7 & 1198,5 & 509,2 & 29,72 \\
\hline $\mathrm{DC}+\mathrm{P}+\mathrm{V}(C D+P+V)$ & 1687,7 & 1224,4 & 463,3 & 27,43 \\
\hline $\mathrm{DC}+\mathrm{A}+\mathrm{V}(C D+G+V)$ & 1691,7 & 1179,3 & 512,4 & 30,29 \\
\hline $\mathrm{DC}+\mathrm{A}+\mathrm{P}(C D+G+P)$ & 1723,4 & 1203,6 & 519,8 & 30,17 \\
\hline $\mathrm{DC}+\mathrm{A}+\mathrm{P}+\mathrm{V}(C D+G+P+V)$ & 1711,6 & 1234,0 & 477,6 & 27,89 \\
\hline $\mathrm{CV}(\%)$ & 4,24 & 5,30 & 10,72 & 9,03 \\
\hline
\end{tabular}

${ }^{1} \mathrm{DC}=$ dieta controle; $\mathrm{P}=$ probiótico; $\mathrm{A}=$ alho; $\mathrm{V}=$ virginiamicina.

${ }^{1} \mathrm{CD}=$ control diet; $P$ = probiotic; $G=$ garlic; $V=$ virginiamycin . 
representou a variável dependente gravidade específica e $X$, a variável independente número de dias de muda forçada. O não atendimento das necessidades nutricionais em cálcio, fósforo e vitamina $\mathrm{D}_{3}$ foi, talvez, o principal fator responsável pelo declínio da qualidade da casca dos ovos nos primeiros três dias da muda forçada. O início da muda forçada deve ser, do ponto de vista fisiológico, uma ótima oportunidade para avaliação da influência de produtos e nutrientes sobre a qualidade da casca dos ovos. Silva \& Santos (2000) mostraram claramente que a oferta de uma fonte de cálcio durante a muda forçada afeta a qualidade da casca e, conseqüentemente, o número de ovos com casca intacta durante e após a muda forçada, sendo o carbonato de cálcio superior ao fosfato bicálcico.

Embora informações anteriores atribuem um possível papel do probiótico na melhoria da qualidade da casca dos ovos (Mohan et al., 1995, Pedroso et al., 1998), este efeito não foi confirmado no presente trabalho, o que concorda com Jadhav et al. (1992) citado por Ferreira \& Oliveira (1996). Segundo Dale (1992), o valor do probiótico como aditivo de rações ainda não está completamente comprovado.

$\mathrm{O}$ peso e a porcentagem de gema, peso e a porcentagem de albúmen e peso e porcentagem de casca não foram afetados pelos aditivos durante a MF (Tabela 5).

\section{Experimento 3. Resultados após a muda forçada}

Durante o terceiro ciclo de produção, não se observou efeito residual dos aditivos e suas misturas em relação ao tratamento testemunha sobre consumo de ração, produção e peso dos ovos, massa e conversão alimentar por massa de ovos e gravidade específica em comparação com os resultados mostrados pelas aves alimentadas com a dieta controle (Tabela 6).

Este resultado concorda com aquele observado por Freitas et al. (2001) com frangos de corte em que a inclusão de $0,2,0,4$ e $0,6 \%$ de alho na ração e $0,0025 \%$ de bacitracina de zinco e $0,001 \%$ de lincomicina não causou efeito positivo sobre o desempenho em relação as aves recebendo a ração sem antimicrobianos.

Novamente, as condições higiênicas das instalações com alojamento das aves em sistema de gaiola com piso suspenso, provavelmente, contribuíram para reduzir o estresse imunológico e a eficácia dos aditivos na promoção do desempenho das aves. Coates et al. (1963) indicaram que, quanto menor o nível de contaminação ambiental, menor a necessidade de uso de antimicrobianos na ração como promotores do desempenho das aves. Segundo Roura et al. (1992), a habilidade dos antimicrobianos na promoção do desempenho das aves depende da extensão do desafio microbiano presente no ambiente, quando a intensidade de desafio decresce, o efeito positivo dos antimicrobianos sobre o desempenho também diminui.

O tratamento contendo somente alho como aditivo diminuiu a produção de ovos em $20 \%$, massa de ovos em $23 \%$ e piorou a conversão alimentar em $16 \%$ em comparação com a dieta controle, estando, provavelmente, relacionadas ao aumento da espessura da parede intestinal. Segundo Hoshiro et al. (2001), a introdução de alho diretamente no estômago provoca irritação da mucosa intestinal, aparecimento de vermelhidão e perda das células do topo das criptas em cães. Segundo Visek (1978), citado por Lancini (1994),

Tabela 5 - Efeitos de diferentes aditivos sobre peso (PG) e porcentagem de gema (\%G), peso (AL) e porcentagem de albúmen $(\% \mathrm{AL})$, peso $(\mathrm{Cs})$ e porcentagem de casca $(\% \mathrm{Cs})$, durante a muda forçada

Table 5 - Effects of different additives on yolk weight (YW) and yolk percentage (\%Y), albumen weight (AW) and albumen percentage $(\% A)$, egg shell weight (ESW) and egg shell percentage (\%ES), during forced molt

\begin{tabular}{|c|c|c|c|c|c|c|}
\hline Tratamentos & PG $(g)$ & $\% \mathrm{G}$ & $\mathrm{AL}(\mathrm{g})$ & $\% A L$ & Cs $(g)$ & $\% \mathrm{Cs}$ \\
\hline Treatments & $Y W$ & $\% Y$ & $A W$ & $\% A$ & $E S W$ & $\% E S$ \\
\hline $\mathrm{DC}(C D)$ & 15,92 & 25,16 & 41,46 & 65,50 & 5,91 & 9,34 \\
\hline $\mathrm{DC}+\mathrm{P}(C D+P)$ & 15,94 & 25,76 & 39,77 & 64,23 & 6,20 & 10,00 \\
\hline $\mathrm{DC}+\mathrm{A}(C D+G)$ & 16,91 & 26,98 & 40,01 & 63,60 & 5,93 & 9,45 \\
\hline $\mathrm{DC}+\mathrm{V}(C D+V)$ & 16,82 & 26,74 & 39,79 & 63,21 & 6,32 & 10,04 \\
\hline $\mathrm{DC}+\mathrm{P}+\mathrm{V}(C D+P+V)$ & 15,76 & 24,76 & 43,60 & 65,80 & 6,01 & 9,43 \\
\hline $\mathrm{DC}+\mathrm{A}+\mathrm{V}(C D+G+V)$ & 16,62 & 27,52 & 39,12 & 62,65 & 5,88 & 9,82 \\
\hline $\mathrm{DC}+\mathrm{A}+\mathrm{P}(C D+P+G)$ & 15,62 & 25,00 & 41,18 & 65,60 & 5,88 & 9,40 \\
\hline $\mathrm{DC}+\mathrm{A}+\mathrm{P}+\mathrm{V}(C D+G+P+V)$ & 15,40 & 23,74 & 44,04 & 67,73 & 5,54 & 8,53 \\
\hline $\mathrm{CV}(\%)$ & 6,38 & 10,05 & 9,98 & 5,48 & 7,97 & 11,60 \\
\hline
\end{tabular}

${ }^{1} \mathrm{DC}=$ dieta controle; $\mathrm{P}=$ probiótico; $\mathrm{A}=$ alho; $\mathrm{V}=$ virginiamicina.

${ }^{1} C D=$ control diet; $P=$ probiotic; $G=$ garlic; $V=$ virginiamycin.

R. Bras. Zootec., v.32, n.6, p.1697-1704, 2003 (Supl. 1) 
Tabela 6 - Efeitos de diferentes aditivos sobre consumo de ração (CR), produção de ovos (PR), peso dos ovos (PO), massa de ovos (MO), conversão por massa de ovos (CMO) e gravidade específica (GE), após a muda forçada

Table 6 - Effects of different additives on feed intake (FI), egg production (EP), egg weight (EW), feed to egg mass ratio (EMR) and specific gravity (SG), after forced molt

\begin{tabular}{lcccccc}
\hline Tratamentos & $\mathrm{CR}(\mathrm{g}$ & $\mathrm{PR}(\%)$ & $\mathrm{PO}(\mathrm{g})$ & $\mathrm{MO}(\mathrm{g})$ & $\mathrm{CMO}(\mathrm{kg} / \mathrm{kg})$ & $\mathrm{GE}$ \\
Treatments & $F I$ & $E P$ & $E W$ & $E M$ & $E M R$ & $S G$ \\
\hline $\mathrm{DC}(C D)$ & 101,20 & 65,88 & 64,37 & 42,51 & 2,51 & 1,068 \\
$\mathrm{DC}+\mathrm{P}(C D+P)$ & 101,01 & 65,95 & 63,86 & 42,13 & 2,41 & 1,069 \\
$\mathrm{DC}+\mathrm{A}(C D+G)$ & 101,03 & 54,81 & 63,34 & 34,64 & 3,00 & 1,090 \\
$\mathrm{DC}+\mathrm{V}(C D+V)$ & 100,96 & 61,62 & 62,66 & 38,62 & 2,65 & 1,068 \\
$\mathrm{DC}+\mathrm{P}+\mathrm{V}(C D+P+V)$ & 101,05 & 59,76 & 62,49 & 37,23 & 2,84 & 1,076 \\
$\mathrm{DC}+\mathrm{A}+\mathrm{V}(C D+G+V)$ & 102,56 & 61,55 & 61,06 & 37,66 & 2,79 & 1,067 \\
$\mathrm{DC}+\mathrm{A}+\mathrm{P}(C D+G+P)$ & 101,07 & 66,95 & 62,08 & 41,58 & 2,57 & 1,070 \\
$\mathrm{DC}+\mathrm{A}+\mathrm{P}+\mathrm{V}(C D+G+P+V)$ & 103,11 & 61,64 & 63,03 & 38,77 & 2,72 & 1,066 \\
$\mathrm{CV}(\%)$ & 2,12 & 16,93 & 3,91 & 17,43 & 21,18 & 2,43 \\
\hline
\end{tabular}

${ }^{1} \mathrm{DC}=$ dieta controle; $\mathrm{P}=$ probiótico; $\mathrm{A}=$ alho; $\mathrm{V}=$ virginiamicina .

${ }^{1} C D=$ control diet; $P=$ probiotic; $G=$ garlic; $V=$ virginiamycin.

o aumento da espessura da parede intestinal causa redução da absorção dos nutrientes e aumenta a taxa de passagem do material em digestão.

Resultados anteriores mostraram que a exposição do plantel a uma situação potencial de estresse, como a muda forçada, deve exacerbar as infecções em poedeiras (Holt \& Gast, 2002). Portanto, nas condições do presente estudo, o método de muda forçada utilizado, com o fornecimento de $10 \mathrm{~g}$ de milho moído em substituição a $110 \mathrm{~g}$ de ração, falhou na indução do estresse imune, provavelmente, em virtude das condições aparentemente sadias das aves, evitando o agravamento de infecções já existentes no plantel. Este fato explica porque o uso dos antimicrobianos na ração não modificou substancialmente o desempenho, peso e porcentagem do baço, como parte do sistema imune, e mortalidade das aves. Este resultado também sugere que a oferta de $10 \mathrm{~g}$ de milho moído durante o período de muda forçada deve controlar o estresse, favorecendo o bem-estar e a manutenção da saúde das aves.

\section{Conclusões}

O uso de alho, virginiamicina e probiótico em rações de poedeiras antes e durante o estresse induzido pela muda forçada é desaconselhável, em virtude de não promoverem melhoria no desempenho das aves durante o ciclo de postura seguinte e onerarem o custo final da ração em relação à ração sem aditivos.

\section{Agradecimento}

À FATEC, pelo fornecimento do probiótico.

\section{Literatura Citada}

ALODAN, MA.; MASHALY, MM. Effect of induced molting in laying hens on production and immune parameters. Poultry Science, v.78, p.171-177, 1996.

BAKER, M.; BRAKE, J.; McDANIEL, GR. The relationship between body weight loss during an iduced molt and posmolt egg production, egg weight and shell quality in caged layers. Poultry Science, v.62, p.409-413, 1983.

BEN NATHAN, D.; HELLER, E.D.; PEREK, M. The effect of starvation on antibody production of chicks. Poultry Science, v.56, p.1468-1471. 1977.

BERTECHINI, A.G.; HOSSAIN, S.M. Utilização de um tipo de probiótico como promotor de crescimento em rações de frangos de corte. In: CONFERÊNCIA DA APINCO DE CIÊNCIAS E TECONOLGIA AVÍCOLAS, 1991, Campinas. Anais ... Campinas: FACTA, 1991. p.1.

BLOCK, E. Chemistry of garlic and onions. Science American, v.252, p.94-99, 1985.

BRAKE, J.; GARLICH, J.D.; PARKHURST, C.R. et al. Physiological profile of caged layers during one production season, molt, and postmolt: organ weight and blood constituents. Poultry Science, v.60, p.2157-2160, 1981.

CECI, L.N.; CURZIO, O.A.; POMILIO, A.B. Effects of irradiation and storage on the flavor of garlic bulbs cv. "Red". Journal of Food Science, v.56, p.44-46, 1991.

COATES, M.E.; FULlER, R.; HARRINSON, G.F. et al. A comparison of the growth of chicks in the Gustafsson germfree apparatus and in a conventional environment, with and without dietary supplements of penicillin. British Journal Nutrition, v.17, p.141-151, 1963.

DALE, N. Probióticos para aves. Avicultura Professional, v.10, p.88-89, 1992.

DAVIS, G.S.; ANDERSON, K.E.; CARROLL, A.S. The effects 
of long-term caging and molt of single comb white leghorn hens on heterophil to lymphocyte ratios, corticosterone and thyroid hormones. Poultry Science, v.79, p.514-518, 2000.

FERREIRA, A.J.P., OLIVEIRA, D.R. Probióticos: naturais, saudáveis e eficientes. Revista Aves e Ovos, v.12, n.8, p.24-29, 1996.

FREITAS, R.; FONSECA, J.B.; SOARES, R.T.R.N. et al. Utilização do alho (Allium sativum L.) como promotor de crescimento de frangos de corte. Revista Brasileira de Zootecnia, v.30, n.3, p.761-765, 2001.

HEMPE, J.M.; LAUXEN, R.C.; FAGAGE, J.E. A rapid determination of egg weight and specific gravity using computerized collection system. Poultry Science, v.67, p.902-907, 1988.

HOST, P.S.; GAST, R.K. Comparison of the effects of infection with Salmonella enteritidis, in combination with an induced molt on serum levels of the acute phase protein, á 1 acid glicoprotein, in hens. Poultry Science, v.81, p.1295-1300, 2002.

HOLT, P.S.; PORTER Jr., R.E. Induced molting increases severity and recrudescence on Salmonella enteritidis intestinal infection in laying hens. In: WORLD'S POULTRY CONGRESS, 19., 1992, Amsterdam. Proceedings ... Amsterdam: 1992. p.346-349.

HOSHIRO, T.; KASHIMOTO, N.; KASUGA, S. Effects of garlic preparations on the gastrointestinal mucosa. Journal of Nutrition, v.131, p.1109S-1113S, 2001.

KING, J.O.L. The effect of pelleting rations with band without an antibiotic on the growth rate of rabbits. Veterinary Research, v.94, p.586-588, 1974.

LANCINI, J.B. Fatores exogenous na função gastrointestinal Aditivos. In: FACTA. Fisiologia da digestão e absorção das aves. Campinas: FACTA, 1994. p.99-126.

MATSUURA, H. Saponins in garlic as modifiers of the risk of cardiovascular disease. Journal of Nutrition, v.131, p.1000S-1005S, 2001.

MOHAN, B.; KADIRVEL, R.; BHASKARAN, M. et al. Effect of probiotic supplementation on serum/yolk cholesterol and on egg shell thickness in layers. British Poultry Science, v.39, p.199-803, 1995.

NATIONAL RESEARCH COUNCIL - NRC. Nutrient requirements of poultry. 9.ed. 1994. 155p.

PEDROSO, A.A.; MORAES, V.M.B.; ARIKI, J. et al. Qualidade de ovos de galinhas poedeiras alimentadas com níveis de proteína e probiótico à base de Bacillus subtillus nas rações. In: REUNIÃO ANUAL DA SOCIEDADE BRASILEIRA DE ZOOTECNIA, 1998, Botucatu. Anais ... Botucatu: Sociedade Brasileira de Zootecnia, 1998. p.321-323.

PRASAD, K.; LAXDAL, V.A.; YU, M. et al. Evaluation of hydroxyl radical-scavenging property of garlic. Molecular and Cellular Biochemistry, v.154, p.55-63, 1996.

ROSTAGNO, H.S.; ALBINO, L.F.T.; DONZELE, J.L. et al. Tabelas brasileiras para aves e suínos: composição de alimentos e exigências nutricionais. Viçosa, MG: Universidade Federal de Viçosa, 2000. 141p.
ROURA, E.; HOMENDES, J.; KLASING, K. Prevention of immunologic stress contributes to the growth-permitting ability of dietary antibiotic in chicks. Journal of Nutrition, v.122, p.2383-2390, 1992.

SILVA, J.H.V.; SANTOS, V. Efeito do carbonato de cálcio na qualidade da casca dos ovos durante a muda forçada. Revista Brasileira de Zootecnia, v.29, n.5, p.1440-1445. 2000.

SILVA, J.H.V.; SANTOS, V.; RIBEIRO, M.L.G. Alta densidade de criação durante o segundo ciclo de postura. In: SUPLEMENTO DA REVISTA BRASILEIRA DE CIÊNCIA AVÍCOLA, 1999, Campinas. Anais ... Campinas: FACTA, 1999. p.1.

SIVAM, G.P. Protection against Helicobacter pylori and other bacterial infections y garlic. Journal of Nutrition, v.131, p.1106S-1108S, 2001.

SONG, K.; MILNER, J.A. The influence of heating on the anticancer properties of garlic. Journal of Nutrition, v.131, p.1054S-1057S, 2001.

SOLCA, F.M.; ROSI, F.; NORDIO-BALDISSERA, C. Histological findings in studies on virginiamycin as auxenic in growing rabbits. In: WORLD RABBIT CONGRESS, Barcelona. Anais... Barcelona: 1980. v.1, p.77-80.

TAKAKI, R.K.; OLIVEIRA, B.L.; BERTECHINI, A.G. Alho (Allium sativum L.): uma nova alternativa na avicultura. In: CONFERENCIA APINCO DE CIÊNCIAS E TECNOlOGiA AVÍCOLAS, 1998, Campinas. Anais ... Campinas: FACTA, 1998. p.28.

TEETER, R.G.; BELAY, T. Broiler management during acute heat stress. Animal Feed Science and Technology, v.58, p.127-142, 1996.

UNIVERSIDADE FEDERAL DE VIÇOSA - UFV. SAEG (Sistema de análises estatísticas e genéticas). Viçosa, $\mathrm{MG}$ : Universidade Federal de Viçosa, 1982. 86p.

VASSALO, M.; FIALHO, E.T.; OLIVEIRA, A.I.G. et al. Probióticos para leitões dos 10 aos $30 \mathrm{~kg}$ de peso vivo. Revista Brasileira de Zootecnia, v.26, n.1, p.131-138, 1997.

YU, T.H.; WU, C.M. Stability of allicin in garlic juice. Journal of Food Science, v.54, p.977-981, 1989a.

YU, T.H.; WU, C.M.; LION, Y.C. Effects of pH adjustment and subsequent heat treatment on the formation of volatile compounds of garlic. Journal of Food Science, v.54, p. 632$635,1989 \mathrm{~b}$.

YOSHIMURA, Y.; OKAMOTO, T.; TAMURA, T. Localisation of MHC class II, lymphocytes and immunoglobulins in the oviduct of laying and moulting hens. British Poultry Science, v.38, p.590-596, 1997.

WALTON, J.R. Modo de acción de los promotores de crescimento. Industria Porcina, v.10, n.2, p.6-11, 1990.
Recebido em: 04/10/02 Aceito em: 03/02/03 